\title{
Thermoelectrically Cooled Short Ram Intake
}

\author{
Sharran S. R. ${ }^{1}$, Sivanesan G. ${ }^{2}$ \\ ${ }^{1,2}$ Department of Mechanical Engineering, RMK Engineering College, Chennai, India
}

\begin{abstract}
The Short Ram Intake is a form of air intake for automobiles with internal combustion engines. It replaces the conventional air intake with a short metal pipe and a conical air filter inside the engine bay. A problem with Short Ram Intakes is that the air entering the intake is at a higher temperature due to the proximity of the engine, which may reduce some power. We are overcoming this issue by making use of a thermoelectric module to reduce the temperature of inlet air, thereby allowing dense air to the inlet manifold.
\end{abstract}

Keywords: Air intake system, Cold air intake, Inlet manifold, Peltier effect, Short ram intake, SRI, TEC - 12706, Thermoelectric cooling

\section{Introduction}

The short ram air intake is the most popular type of intake on the market. This intake is designed to simply replace the factory intake with a new smooth pipe and an open element air filter. Due to this, the cost is less than a cold air intake, and also is much easier to install. Short ram intakes (SRI) look to increase power by reducing the amount of restriction on the intake air. In many vehicles, the intake air passes through a resonator and silencer box to help reduce induction noise. This restriction can limit airflow. A short ram eliminates the resonator and filter box, giving the air a short travel distance and hopefully increasing power. That said, it's pulling air from the engine bay, thus the intake air will be warmer than by using a cold air intake such that it's design allows for engine heat to have an easier path into the intake system, reducing horsepower and torque than an equivalent cold air intake. In this system, we are overcoming this issue by make using of a thermoelectric module to make use of the heat from the engine and a minor current from a battery source to cool the inlet air, thereby increasing its density allowing more oxygen for a complete combustion.

\section{Exsisting Problem}

Though Short Ram Intake proves penny wise friendly, it is bound to have certain limitations. Since, the intake air filter is located right inside the engine bay, it is more likely to pull in warm air, thereby heated air enters the combustion chamber reducing the oxygen content which inturn affects the combustion process. Warmer air is less oxygen rich and does not allow for a very clean burning of fuel thus power gains are minimal. Also the torque is comparatively less than other induction technologies. The Intake of Warm/Hot air is the main source of problem for the above mentioned Issues.

\section{Proposed Solution}

The Solution for exsisting problem with the short ram intake can be overcome by supplying cold air to the engine inlet manifold. This solution can be proved effective by relating it with a Cold Air Intake (CAI) which supplies coldest air possibly available to the engine which inturn provides the most horsepower to the engine better than any other intake methods. Although, this system has proved effective, it is bound to have complexities and technical knowledge for installation. It is found to be more expensive. On the other hand,
Short Ram Intake has better throttle response compared to Cold Air Intake due to increased air flow and better fuel economy. Hence, we have proposed to incorporate the benefits of Cold Air Intake into Short Ram Intake by making use of a thermoelectric module, providing the necessary cooling for the inlet air.

\section{Technical Background}

Thermoelectric cooling uses the Peltier effect to create a heat flux between the junction of two different types of materials. A Peltier cooler, heater, or thermoelectric heat pump is a solid-state active heat pump which transfers heat from one side of the device to the other, with consumption of electrical energy, depending on the direction of the current. Such an instrument is also called a Peltier device, Peltier heat pump, solid state refrigerator, or thermoelectric cooler (TEC). It can be used either for heating or for cooling, although in practice the main application is cooling. It can also be used as a temperature controller that either heats or cools.

\subsection{Thermo Electric Module 12706}

A thermoelectric module is an electrical module, which produces a temperature difference with current flow. The emergence of the temperature difference is based on the Peltier effect designated after Jean Peltier. The thermoelectric module is a heat pump and has the same function as a refrigerator. It gets along however without mechanically mobile construction units (pump, compressor) and without cooling fluids. The heat flow can be turned by reversal of the direction of current.

Thermoelectric coolers operate by the Peltier effect (which also goes by the more general name thermoelectric effect). The device has two sides, and when DC current flows through the device, it brings heat from one side to the other, so that one side gets cooler while the other gets hotter. The "hot" side is attached such that it remains at ambient temperature ie. engine surface temperature in our case, while the cool side goes below room temperature. In some applications, multiple coolers can be cascaded together for producing lower temperatures. Thermoelectric coolers are solid state heat pumps that operate on the Peltier effect, the theory that there is a heating or cooling effect when electric current passes through two conductors. A voltage applied to the free ends of two dissimilar materials creates a temperature difference. With this temperature difference, Peltier cooling will cause heat to move from one end to the other. A 


\section{International Journal of Science and Research (IJSR) \\ ISSN (Online): 2319-7064}

Index Copernicus Value (2013): 6.14 | Impact Factor (2014): 5.611

typical thermoelectric cooler will consist of an array of p- and ntype semiconductor elements that act as the two dissimilar conductors. The array of elements is soldered between two ceramic plates, electrically in series and thermally in parallel. As a dc current passes through one or more pairs of elements from $\mathrm{n}$ - to $\mathrm{p}$-, there is a decrease in temperature at the junction ("cold side") resulting in the absorption of heat from the environment. The heat is carried through the cooler by electron transport and released on the opposite ("hot") side as the electrons move from a high to low energy state. The heat pumping capacity of a cooler is proportional to the current and the number of pairs of $n$ - and p- type elements (or couples).

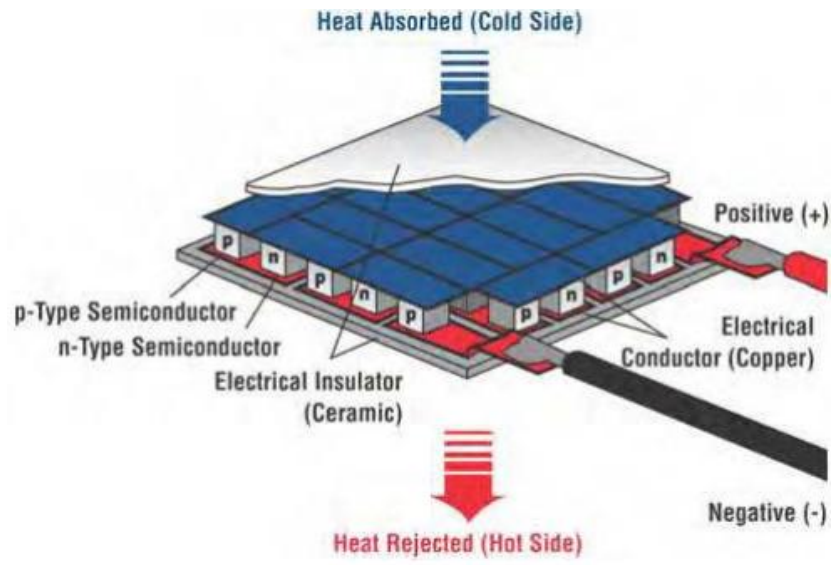

Figure 1: Cut Section view of a Thermoelectric Module

\begin{tabular}{|c|c|}
\hline \multicolumn{2}{|c|}{ TEC 12706 MODULE } \\
\hline Voltage & $12 \mathrm{~V}$ \\
\hline Umax (V) & $15.4 \mathrm{~V}$ \\
\hline Imax (A) & $6 \mathrm{~A}$ \\
\hline QMax (W) & $92 \mathrm{~W}$ \\
\hline Internal resistance & $1.98 \mathrm{Ohm}+/-10 \%$ \\
\hline HS Code & 854150 \\
\hline Dimensions & $40 \mathrm{~mm} \times 40 \mathrm{~mm} \times 3.6 \mathrm{~mm}$ \\
\hline Certification & RoHS \\
\hline
\end{tabular}

\begin{tabular}{|c|c|c|}
\hline Hot Side Temperature $\left({ }^{0} \mathrm{C}\right)$ & $25^{0} \mathrm{C}$ & $50^{0} \mathrm{C}$ \\
\hline Qmax (Watts) & 50 & 57 \\
\hline Delta Tmax $\left({ }^{0} \mathrm{C}\right)$ & 66 & 75 \\
\hline Imax (Amps) & 6.4 & 6.4 \\
\hline Vmax (Volts) & 14.4 & 16.4 \\
\hline Module Resistance (Ohms) & 1.98 & 2.30 \\
\hline
\end{tabular}

From the above mentioned specifications of the thermo electric module the maximum temperature difference is $75^{\circ} \mathrm{c}$

$\mathrm{T}_{\mathrm{h}-\mathrm{T}_{\mathrm{c}}}=75^{\circ} \mathrm{c}$

where,

$\mathrm{T}_{\mathrm{h}}$ is hot side temperature of TEC

$\mathrm{T}_{\mathrm{c}}$ is cold side temperature of TEC

It is assumed that the heat available from engine body is around $80^{\circ} \mathrm{C}$

So,

$\mathrm{T}_{\mathrm{c}}=5^{\circ} \mathrm{c}$

Assuming that the heat is transferred from cold side of the TEC to the inlet air without any loses and considering isentropic equations, the pressure change of inlet air due to temperature decrease is,
$\mathrm{P}_{2} / \mathrm{P}_{1}=\left(\mathrm{T}_{2} / \mathrm{T}_{1}\right)^{\mathrm{y} / \mathrm{y}-1}$

Here,

$\mathrm{P}_{1}$ is initial pressure $=1.0132 \mathrm{bar}$

$\mathrm{P}_{2}$ is final pressure, to be found

$\mathrm{T}_{1}$ is initial temperature of inlet air $=32^{\circ} \mathrm{c}$ (assumed)

$\mathrm{T}_{2}$ is final temperature after thermo electric cooling $=5^{\circ} \mathrm{c}$ $y=1.4$

By calculations the final pressure $\mathrm{P}_{2}$ is found to be $1.401 \mathrm{bar}$.

Thus the pressure of inlet air is increased from 1.0132bar to 1.401bar

\subsection{Short Ram Intake}

A short ram intake is just that, short. Because of its dimensions, the intake-pipe does not expand a far distance from the intake manifold; therefore, the air-filter stays close to the engine. Short Ram Intakes or (SRIs) are a great alternative to a cold air intake due to significantly lower cost. The tubing on a shortram is wider and much shorter than a CAI. The wider tubing allows for the greater volume of air-flow to the engine over that of a CAI. Short Ram intakes are much easier to install and require the most minimal knowledge when installing. However, it's very important to understand that because the intake is located near the engine, the air being pulled in is warmer than a CAI. Warmer air is less oxygen

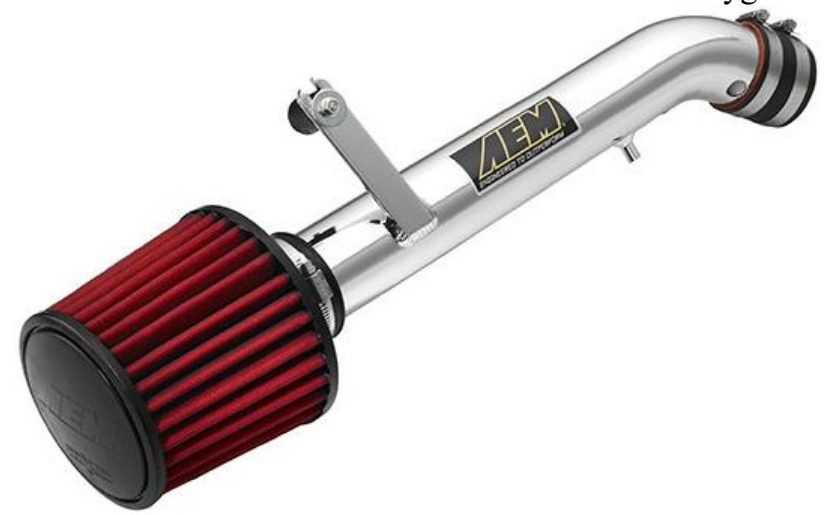

Figure 2: Short Ram Intake with inlet air filter

rich and does not allow for a very clean burning of fuel thus power gains with a short ram intake are minimal but fuel economy is increased over that of a cold air intake. To recap slightly, a cold air intake works by pulling in cooler more oxygen rich air while a short ram pulls in warmer air but at a faster rate

\section{Construction}

Thermoelectric cooled short ram intake system consists of a tubing which is wider than that of a traditional intake manifold and placed closer to the engine. An Air filter is provided at the front end of the tubing and thermoelectric modules are placed at the other end so that the inlet air is completely 


\section{International Journal of Science and Research (IJSR) \\ ISSN (Online): 2319-7064}

Index Copernicus Value (2013): 6.14 | Impact Factor (2014): 5.611

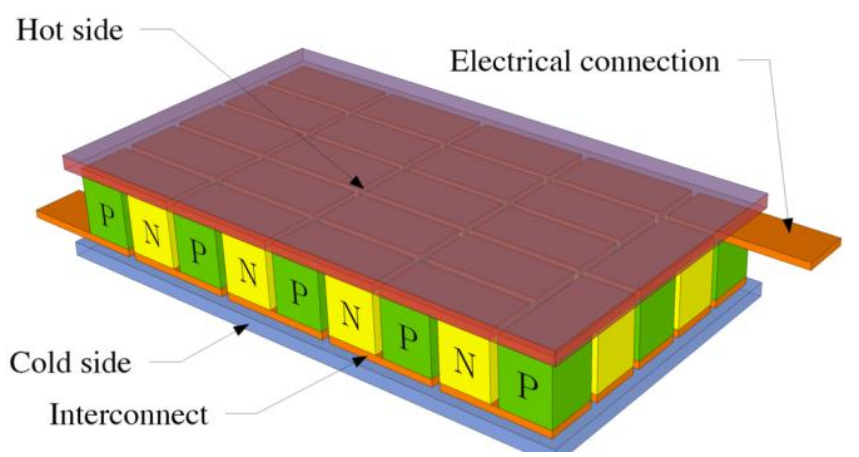

Figure 3: Diode arrangement inside a thermoelectric module

cooled by the process of convection. The Short Ram Tubing is placed in such a way that the hot junction of the thermoelectric module is subjected to a surface contact with the hot engine body so that it provides the necessary heat for the hot junction of the thermoelectric module and also the cold junction of the thermoelectric couple is placed in such a manner that it comes in direct contact with the inlet air flow. Due to convection of heat from the inlet air to the cold junction, Inlet air gets cooled. This eventually makes the air denser. The current required for the operation of thermoelectric module is provided by making use of an existing battery source present in an automobile.

\section{Detailed Description}

This system makes use of thermoelectric cooling in short ram

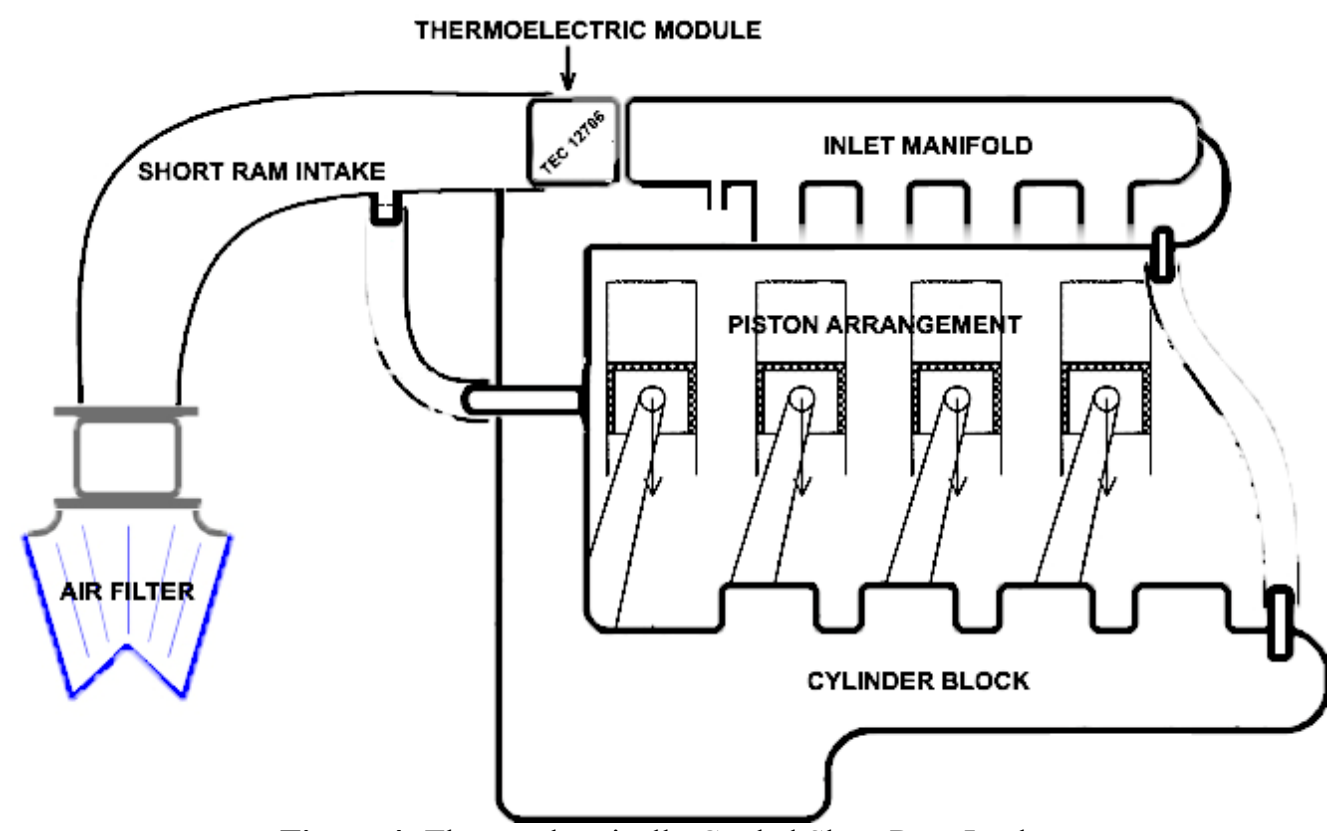

Figure 4: Thermoelectrically Cooled Short Ram Intake

intake to overcome the limitations of Short ram intake. The thermo electric module is positioned such that it is located right before the throttle body in the inlet manifold. TEC module is sited is such a way that one of its side (hot side) touches the engine body and makes use of the engine heat to produce the hot junction in one side. The other side (cold side) of the TEC comes in direct contact with the inlet air. The current required for the TEC is provided from a DC battery source which is previously present in the automobile. Hence the provided hot junction (engine body) and current (from battery) brings Peltier effect into working in the TEC to produce a cold junction. Peltier observed that if a current is passed through a single junction of the type described above, a temperature difference is created between the two junctions of the semiconductor material. This observation is called the Peltier effect. And now this cold junction is in direct contact with the inlet air. The inlet air gets cooled through the process of forced convection which is be employed to facilitate the transfer of heat from the surface of the thermoelectric to the surrounding air thereby reducing the pressure which inturn provides dense air. Dense air carries more oxygen which helps better combustion, increased power and improved torque. The presence of thermoelectrically cooled short ram intake aids ready availability of air. It en- sures hindrance free supply of cold air to the combustion chamber in large volumes. The wider tubing allows for the greater volume of air-flow to the engine. This Intake system suits well for spark ignition engines where the combustion process is initiated by spark from the spark plug, where a change in temperature of the charge is less likely to affect the ignition process.

\section{Conclusion}

Thus with the development of this thermoelectrically cooled short ram intake, the benefits of both cold air intake and short ram intake can be collectively achieved in the same engine thus providing high performance motoring. This system makes use of the heat liberated from the engine, rather than depending upon an additional source for heat. We can achieve, Better Combustion Effeciency, Increased Power, Amplified Torque with this Intake system. This setup is highly installation friendly and requires no complex installation procedures like that of a CAI. 


\section{International Journal of Science and Research (IJSR) \\ ISSN (Online): 2319-7064}

Index Copernicus Value (2013): 6.14 | Impact Factor (2014): 5.611

\section{Acknowledgement}

We are very much privileged to express our gratitude to our college. Without the immense support of the Head of our Department, this paper would not have been a reality. We express our sincere thanks to all our faculty members for guiding us to finish this paper successfully. We are also thankful to our parents for their kind cooperation.

\section{References}

[1] This website "http://shortram.com/air-intake-systemexplained/"

[2] This web site "http://www.redline360.com/garage/coldair-intake-vs-short-ram-intake-which-is-better"

[3] Patent No. US 6,758,193 B1K. Landecker, in Proceedings of the 1st International Conference on

[4] A.F. Ioffe, Semiconductor Thermoelements and Thermoelectric Cooling (Infosearch, London, 1957), p. 36

[5] R.B. Horst, L.R. Williams, in Proceedings of the 3rd International Conference on Thermoelectric Energy Conversion, Arlington, Texas (IEEE, New York, 1980), p. 183.

[6] T.P. Hogan, T. Smith, in Thermoelectrics Handbook: Macro to Nano, ed. by D.M. Rowe (CRC Taylor and Francis, Boca Raton, 2006), p. 12-5

[7] Thermoelectric Energy Conversion, Arlington, Texas (IEEE, New York, 1976), p. 150 